MATEC Web of Conferences 13, 04003 (2014)

DOI: $10.1051 /$ matecconf/ 20141304003

(C) Owned by the authors, published by EDP Sciences, 2014

\title{
Finite Element Modelling of a Pattern of Temperature Distribution during Travelling Heat Source from Oxyacetylene Flame
}

\author{
Adam Umar Alkali ${ }^{1, a}$, Turnad Lenggo Ginta ${ }^{2}$ and Ahmad Majdi Abdul-rani ${ }^{2}$ \\ ${ }^{1}$ Department of Mechanical engineering, Universiti Teknologi Petronas,Bandar Seri Iskandar, 31750 \\ Tronoh, Ipoh, Malaysia \\ ${ }^{2}$ MOR, Biomedical Technology, Universiti Teknologi PETRONAS, Bandar Seri Iskandar, \\ 31750 Tronoh, Ipoh, Malaysia
}

\begin{abstract}
A 3D Finite element model was developed to analyse the conduction temperature distribution on type 304 stainless steel workpiece. An experimental heatingonly test was conducted using the input parameters from FEM model which predicted the temperature field on the 304 stainless steel work pieces. Similar temperature pattern was noticed for both the FEM model as well as the experimental. Conduction was observed to be the dominant heat transfer mode. Maximum temperatures were observed to occur at the regions of contact between flame heat and the work pieces. Maximum temperature attained during the two investigated runs was $355^{\circ} \mathrm{C}$. Even so austenite crystal morphology was retained on the preheated workpiece.
\end{abstract}

\section{Introduction}

Machining of hard materials through workpiece preheated at localized area called thermally enhanced machining (Hence forth TEM) has created wide interest among researchers. Despite its reported benefits over both conventional and non-conventional processes [1,2] the TEM process remained within a research test bench and yet to meet wider industrial application. This set back can be attributed to the difficulty in controlling the parameters of the heat source like the spot size and scanning speed of the travelling heat source which eventually influences the temperature distribution as well as heat affected zone on the machined workpiece. Oxyfuel flame is one of the viable heat source used for this specialized process [3,5]. Various heating techniques have been utilized for thermally enhanced machining, most recent uses laser and plasma heat [6, 7]. However, heating source is not the only concern in TEM process; rather, proper selection of the heating parameters that may justify production cost and achieving high machining performance. In various practices, these particular parameters determine failure or success of processes. Therefore, regulating them will prove to be crucial. Tosun and Ozler [8] used liquid petroleum gas flame to study tool life in hot machining using artificial neural network and regression method. Maity and Swain [9] used liquid petroleum gas flame to investigate tool life improvement and developed an expression of tool life as a function of temperature, cutting speed, feedrate and depth of cut. Ranganathan et al, [5] used flame heating at

\footnotetext{
${ }^{a}$ Corresponding author : adamalkalee@yahoo.com
}

This is an Open Access article distributed under the terms of the Creative Commons Attribution License 2.0, which permits unrestricted use, distribution, and reproduction in any medium, provided the original work is properly cited. 
varied temperature range to study TEM characteristics. They applied ANN and response surface methodology to evaluate surface roughness of the workpiece. The most common investigated parameters in TEM with Oxyfuel flame has been generally the end results: tool life, surface roughness, cutting force etc. Several factors responsible for inducing undesirable structural changes on the workpiece materials which also evaluates the effectiveness of TEM, are not investigated in the wide published literature. Frequently used methods for evaluating the effectiveness of a TEM process has been the control of the temperature distribution as a result of the external heat source. For this purpose, finite element method has been used in this study to predict the velocity of the moving heat source along with the temperature field on the workpiece. Experimental setup was made to investigate the input parameters used in the FEM model.

\section{Experimental Procedures}

Type 304 stainless steel was used in this study. Its chemical composition as well as mechanical properties is provided in Table 1. In order to obtain a reasonable result, test samples for metallurgical test having a dimension $125 \times 50 \times 4.5 \mathrm{~mm}$ were carefully cut by wire EDM so as not to distort the metallurgical properties of the material. Oxyacetylene gas flame set to Oxygen/acetylene ratio of 1.52 was used to preheat the cut samples utilizing a neutral flame. 8 point Omega - DAQPRO 5300 data logger attached to K-type thermocouples were used to capture the reading as the temperature of the steel was elevated by the travelling heat sourced from the oxyacetylene flame. The torch was held at an approximate gap of $3 \mathrm{~mm}$ from the work material surface at $90^{\circ}$. This small gap enabled the rapid temperature rise of the material because acetylene has most Btu's concentrated in the inner flame and this resulted to a quick heating potential. The setup shown in Figure 1, investigated varying flame scanning speed as it travels along the span of the workpiece length. A piece of $10 \mathrm{~mm} \times 10 \mathrm{~mm}$ was later cut by wired EDM process to prepare sample for metallographic observations through hot mounting, polishing and etching in accordance to ASTM E-3. All metallography were obtained at the same magnification of 100X using Nicon optical microscope, Model Eclipse ME 600P.

Table 1. Chemical composition (wt.\%) of Type 304 stainless steel.

\begin{tabular}{llllllll}
\hline $\mathrm{Ni}$ & $\mathrm{Cr}$ & $\mathrm{S}$ & $\mathrm{Mn}$ & $\mathrm{P}$ & $\mathrm{Si}$ & $\mathrm{C}$ & $\mathrm{Fe}$ \\
\hline 8.240 & 18.590 & 0.015 & 1.501 & 0.025 & 0.448 & 0.068 & $\mathrm{Bal}$ \\
\hline
\end{tabular}

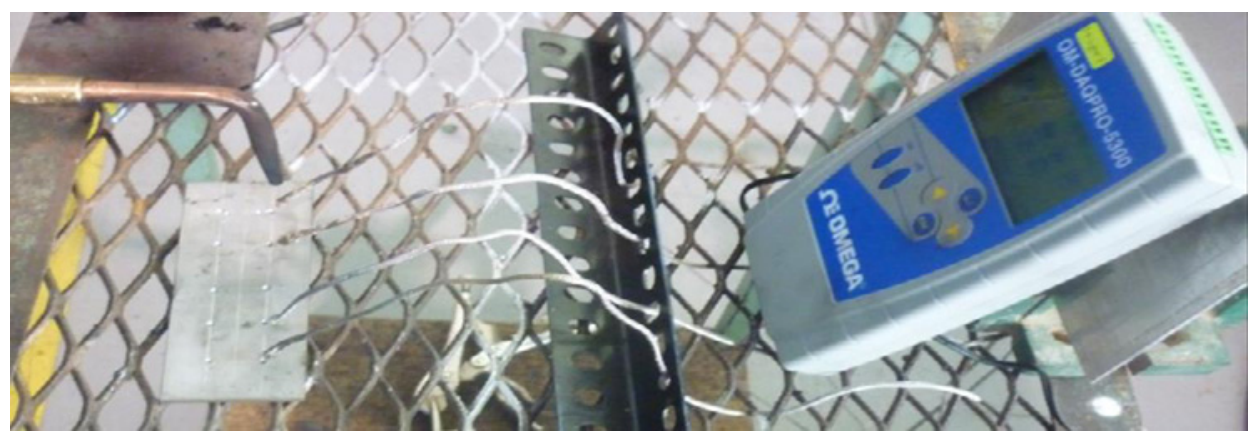

Figure 1. Temperature reading setup obtained from travelling heat sourced from oxyacetylene flame 


\section{Results and Discussion}

Figure 2a shows the micrograph of a preheated sample of type 304 stainless steel, while Figure $2 \mathrm{~b}$ indicates an average hardness plots on the preheated sample until maximum temperature of $355^{\circ} \mathrm{C}$. The hardness test revealed an average of HRC 27 on the preheated surface as against HRC 29 on the initial grain structure. However, beneath the surface $5 \mathrm{~mm}$ downwards, averaged hardness HRC 28.35 was maintained. Even so, austenite crystal configuration was retained after the preheat as evident in the micrographs below.

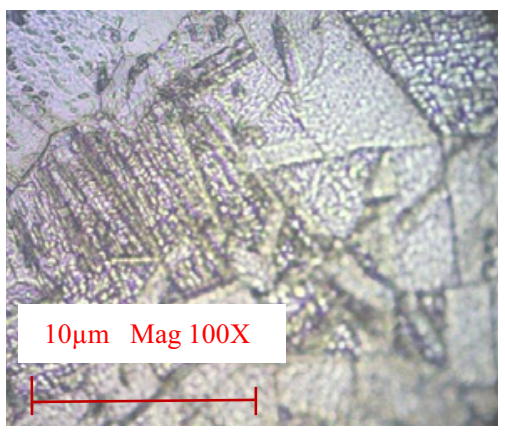

(a)

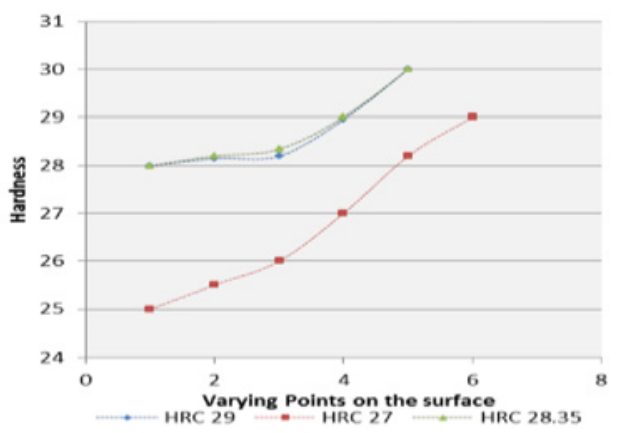

(b)

Figure 2(a) Micrograph of type 304 stainless steel preheated sample to $355^{\circ} \mathrm{C}$ along with their average surface hardness plots (b).

The speed of the travelling heat sourced from oxyacetylene flame was purposely varied $\mathrm{Sv}, 2 \mathrm{~mm} / \mathrm{sec}$ and $1.24 \mathrm{~mm} / \mathrm{sec}$. Maximum temperature attained during the two investigated runs was $355^{\circ} \mathrm{C}$. It was observed that speed of the travelling heat source influences the temperature rise. During flame travelling speed of $1.24 \mathrm{~mm} / \mathrm{sec}$, the maximum temperature attained was $355^{\circ} \mathrm{C}$ whereas $200^{\circ} \mathrm{C}$ was the maximum attained at speed of $2 \mathrm{~mm} / \mathrm{sec}$. The temperature rise instantly from ambient $21.3^{\circ} \mathrm{C}$ to average of $40.95^{\circ} \mathrm{C}$ in less than 10 seconds when the flame travels at $1.24 \mathrm{~mm} / \mathrm{sec}$. Thereafter, the temperature steadily increases as the heat sources travels along the span of the work piece. This trend was noticed from both the FEM model as well as the experimental result shown in Figure 3. The process was monitored with OM - DAQPRO - 5300, 8 point data logger attached to a K-type thermocouples placed at 4 points, $20 \mathrm{~mm}$ apart and approximately, $5 \mathrm{~mm}$ away from the heat source. However, the pattern of this temperature field was best informed in the FEM model.

\subsection{D Transient Thermal Model}

Ansys V.14 was used to develop a 3D finite element transient thermal model in order to predict the pattern of the temperature distribution from a travelling heat sourced from Oxyacetylene flame. A solid 70 element was used with element edge size of $0.002 \mathrm{~mm}$. The geometry of the model was created to mimic the actual size of the experimental work piece. This included the temperature dependent properties like Thermal conductivity, specific heat capacity and density of the material as obtained elsewhere in [10]. Heat flux was used as the surface load, given the actual flame heat of oxyacetylene at the ratio of 1.52 as calculated from the stoichiometric equation 1and 2 below [11 - 13] This was divided by the area around which the element will received the surface load at a particular load step. It was observed in the FEM model that the temperature was always maximum every time, at the region where the heat is in contact with the substrate. Conduction was the dominant heat transfer mode occurring. This was informed from the spatial distribution of the temperature as shown in the FEM model in Figure 4, and elsewhere in [14]. The highest temperature obtained while the flame travels at speed of $1.24 \mathrm{~mm} / \mathrm{sec}$ was $445^{\circ} \mathrm{C}$ as against the $350^{\circ} \mathrm{C}$ obtained in the experimental record. This variation can be attributed to the differences from the spot with which the temperature record was obtained. For example, the temperature readings given by the thermocouples are obtained $5 \mathrm{~mm}$ away 
from the flame spot diameter, whereas the FEM model gives the spatial distribution of the temperature at discreet region on the surface of the workpiece. In which case, the maximum temperatures occurred at the exact regions of contact between heat and the workpiece. Figure 4 shows the incidents from the simulations model.

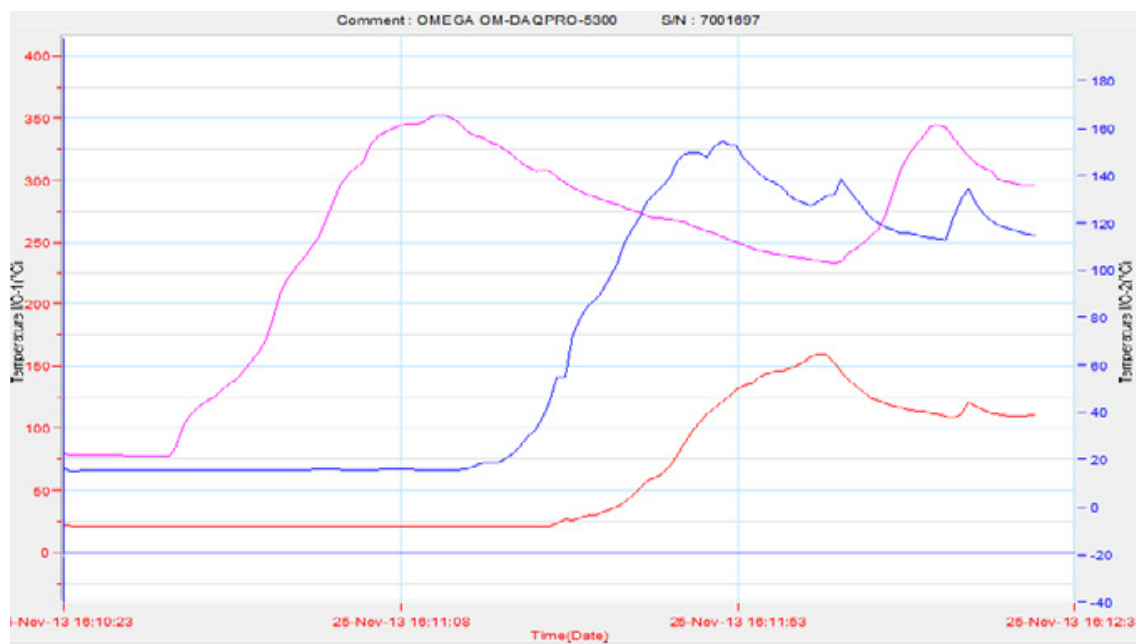

Figure 3. Temperature Gradient of type 304 Stainless Steel at flame speed of $2 \mathrm{~mm} / \mathrm{sec}$

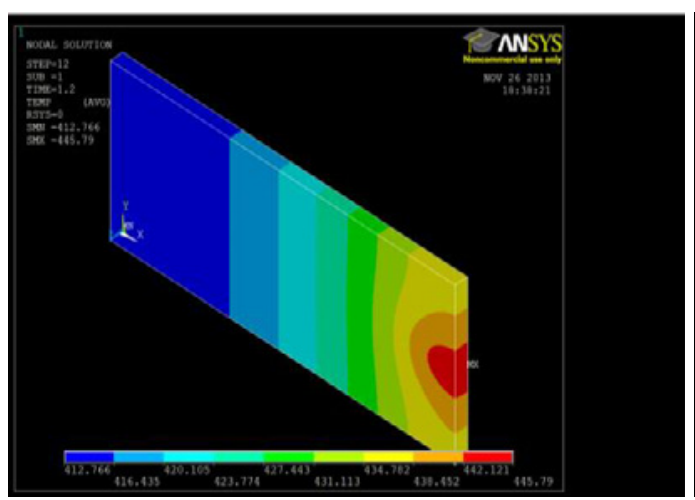

(a)

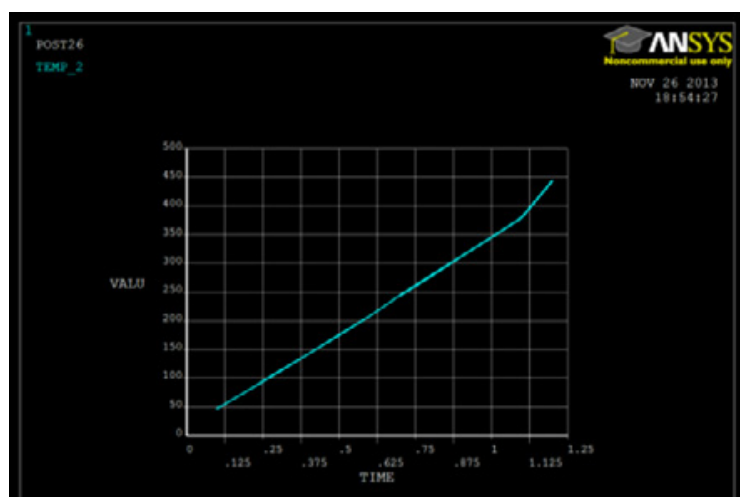

(b)

Figure 4. Transient Thermal Model of a Nodal Temperature Distribution at 102secs while the flame travels at $1.24 \mathrm{~mm} / \mathrm{sec}$.

$$
\begin{aligned}
& 2 \mathrm{C}_{2} \mathrm{H}_{2}+5 \mathrm{O}_{2}=4 \mathrm{CO}_{2}+2 \mathrm{H}_{2} \mathrm{O}+\operatorname{HEAT}(\text { ENERGY }) \\
& \left.\left.-Q=\sum\left[\Delta H_{f}^{0}\right]_{p} \times \dot{n}_{p}\right]-\sum\left[\Delta H_{f}^{0}\right]_{f} \times \dot{n}_{f}\right]
\end{aligned}
$$

Elements temperature at a region where the heat was applied are represented by the nodal temperature given in Figure $4 \mathrm{c}$ because the finite elements receives directly the load applied on the nodes. The temperature trend can be noticed having mimicked that on the spatial surface of the work piece. 


\section{Conclusions}

A 3D finite element of a transient thermal analysis was developed to investigate the behavior of a travelling heat sourced from oxyacetylene gas flame. The FEM model presented the spatial distribution of the temperature at discreet region on the surface of the work piece, in which case the maximum temperatures were observed to occur at the regions of contact between the heat and the workpiece. The speed of the heat sourced was observed to be a factor which influences the temperature rise. Thus, slower speed may result to higher temperature rise, and larger heat affected area. Within the tested speed ranges, thermal distortion was not accrued. It was resolved that the FEM model result concurs with experimental result.

\section{References}

[1] T. L. Ginta, A. Amin, M. A. Lajis, A. Karim, C. Daud, and M. Radzi, Eur. J. of Sci. Res., 27, 384-391, (2009).

[2] A. Amin, S. B. Dolah, M. B. Mahmud, and M. Lajis, J. of Mater. Process. Tech, 201, 466-470, (2008).

[3] L. Özler, A. Inan, and C. Özel, Int'l J. of Mach. Tools and Manuf, 41, 163-172, (2001).

[4] N. Tosun and L. Ozler, The Int'l J. of Adv. Manuf. Tech., 23, 777-782, (2004).

[5] S. Ranganathan, T. Senthilvelan, and G. Sriram, Mater. and Manuf. Processes, 25, 1131-1141, (2010)

[6] C. R. Dandekar, Y. C. Shin, and J. Barnes, Int'l J. of Mach. Tools and Manuf., 50, 174-182, (2010).

[7] C. E. Leshock, J.-N. Kim, and Y. C Shin, Int'l J. of Mach. Tools and Manuf., 41, 877-897, (2001).

[8] N. Tosun and L. Özler, J. of Mater. Process. Tech., 124, 99-104, (2002).

[9] K. P. Maity and P. K. Swain, J. of Mater. Process Tech., 198, 344-349, (2008).

[10] C. Metals. SS 316L in Sheet, Plate, Bar, (2013).

[11] D. Drysdale, "An Intro. to Fire Dynamics," 2nd, 18-108, 1999.

[12] B. Karlsson. and. J. G. Quintiere, "Enclosure Fire Dynamics," 11-140, (2000).

[13] A. J. Ghajar and K. Bang, Heat transfer Eng, 14, 48-59, (1993).

[14] R. Singh, M. J. Alberts, and S. N. Melkote, Int'l J. of Mach. Tools and Manuf., 48, 994-1004, (2008). 